\title{
Networking
}

\section{The present status and future role of family doctors: a perspective from the International Federation of Primary Care Research Networks}

\author{
Waris Qidwai ${ }^{1}$, John W. Beasley ${ }^{2}$ and Francisco J. Gomez-Clavelina ${ }^{3}$ \\ ${ }^{1}$ Department of Family Medicine, The Aga Khan University, Karachi, Pakistan \\ ${ }^{2}$ Department of Family Medicine, University of Wisconsin School of Medicine and Public Health, USA \\ ${ }^{3}$ Family Medicine Department, National Autonomous University of Mexico, Mexico
}

\begin{abstract}
Background: Health care systems are changing around the world; family doctors need to adapt and prepare for future challenges. Aim: To consider the present status of family doctors, anticipated changes in health care systems, the challenges these will bring and possible solutions. Collection of information: Collaborative enquiry amongst members of the International Federation for Primary Care Research Networks (IFPCRN). Six strategic questions were addressed by 37 contributors from 23 countries. Responses were collated and contributors invited to further comment on the interim report. Findings: Present status: Despite wide variability, common problems relate to delivery systems, funding and policy, lack of evidence-based medical practice, education and research. Role of family doctors: There is wide variability in roles and often poor interaction with other caregivers. Anticipated changes: An expansion of the family physician model is anticipated, alongside shortages of family doctors in the face of increased health care needs, increased complexity of problems and the shift to ambulatory care. Advances in information technology may be useful. Anticipated challenges and proposed actions: Address quality issues. This requires audit and quality assurance, promoting adaptability, promoting group practices and teamwork, coordinating care, incorporating information technology and ensuring ethical relationships with industry. Improve education and continuing professional development: Improved education and continuing professional development are needed, as are measures to prevent burnout and retain the workforce. Develop a robust research enterprise: Research in primary care is needed to develop relevant guidelines. Improve support for family doctors: Providing excellent patient care is essential for improved status and support. Achieving this requires engagement with policy makers, academic institutions and the public. Conclusions: While there is great variability across different countries, common themes relate to present status, anticipated changes in health systems and the responses needed from family medicine.
\end{abstract}

Key words: family medicine; family physicians; health care delivery; international; primary health care

Received: June 2007; accepted: May 2008

Correspondence to: Waris Qidwai, Department of Family Medicine, The Aga Khan University, Stadium Road, PO Box: 3500, Karachi 74800, Pakistan. Email: waris.qidwai@aku.edu

(C) 2008 Cambridge University Press 


\section{Introduction}

Primary care is the provision of integrated, accessible health care services by clinicians who are accountable for addressing a large majority of personal health care needs, developing a sustained relationship with patients and practising in the context of the family and community (Donaldson et al., 1996). By virtue of its broad-based, frontline and holistic outlook, primary care is essential for the success and sustainability of any health care system. Family doctors form an important component of the primary health care team. In one study, ten industrialized countries were compared, on the basis of the primary health care system, 12 health indicators and population satisfaction, with overall costs of the systems. A general concordance was found among these three characteristics, highlighting the importance and impact of primary health care on health indicators and the costs of health care (Starfield, 1991). Despite such evidence, the future of primary care continues to be subject to debate (Sox, 2003). Among the consequences of this internationally are recruitment problems, which aggravate shortages of primary care physicians despite increased demand.

Health care systems are comprised of all the people, structures, processes and actions, the primary purpose of which is to promote, protect, restore, maintain and improve the health of the population (World Bank, 1993). Changes in health care systems pose challenges for health care professionals. Family doctors need to be aware of the potential changes in health care systems for them to optimize patient care and develop plans to meet these challenges.

\section{Collaborative enquiry}

At the meeting of the International Federation for Primary Care Research Networks (IFPCRN) held at Orlando, Florida, USA, in October 2004, a decision was made to conduct a collaborative enquiry (Bray et al., 2000) on the present status and future role of family doctors among the network members. Following discussions, the three lead authors developed six questions to structure the enquiry:

1. How is primary care delivered in your country? How is it funded? What are the problems?

2. What is the role of family doctors in the delivery of primary care? How is their care integrated with care by others (quacks, traditional healers, sub-specialists)?

3. How will the system and needs of the population change within the next 10 years?

4. How can family doctors and organized family medicine help to meet these changing needs?

5. What challenges will this pose for family doctors and organized family medicine?

6. How can these challenges best be met through system change, education and research? What resources will this require?

We used the IFPCRN membership list to invite members to participate as contributors from their country or region. Thirty-seven participants from 23 countries contributed to the enquiry. The six questions were sent electronically to the participants. They were asked to provide information from their region, restricted to one page and within a specified period. The responses were reviewed on submission and integrated by the authors into a single manuscript in line with the study objectives. The lead authors verified the submitted information. More than one contributor was recruited from some regions/countries to help ensure accuracy of information provided. The contributors reviewed the draft before the paper was finalized. Countryand region-specific information provide examples of the broad range of issues identified.

\section{Findings}

The 37 participants were from 23 countries. Table 1 provides basic information on each of these countries. Table 1 illustrates the wide variation in health indicators across the participating countries. For example, life expectancy for men is 46 years in Nigeria compared with 78 years in Australia (World Health Organization, 2006).

The responses from the participants were grouped under a number of themes. Information under these themes is presented below with reference to the supporting literature.

\section{Question 1. Present status of primary care}

\section{Delivery of primary care}

Developed and functional structures for the delivery of primary care exist in several countries, 
Table 1 Basic information on participating countries ${ }^{a}$

\begin{tabular}{|c|c|c|c|c|c|c|c|}
\hline \multirow[t]{2}{*}{ Country } & \multirow[t]{2}{*}{$\begin{array}{l}\text { Population } \\
\text { (million) }\end{array}$} & \multirow{2}{*}{$\begin{array}{l}\text { Number of registered } \\
\text { physicians (per } 1000 \\
\text { population) }\end{array}$} & \multicolumn{2}{|c|}{$\begin{array}{l}\text { Life expectancy } \\
\text { (years) }\end{array}$} & \multirow{2}{*}{$\begin{array}{l}\text { Per capita } \\
\text { income } \\
\text { (US\$) }\end{array}$} & \multirow{2}{*}{$\begin{array}{l}\% \text { GNP } \\
\text { spent on } \\
\text { health }\end{array}$} & \multirow{2}{*}{$\begin{array}{l}\text { Post-graduate } \\
\text { training in family } \\
\text { medicine exists }\end{array}$} \\
\hline & & & Male & Female & & & \\
\hline \multicolumn{8}{|l|}{ Africa } \\
\hline Egypt & 71.931 & $0.54(2003)$ & 65 & 69 & 1390 & 4.9 & Yes \\
\hline Kenya & 31.987 & $0.14(2004)$ & 50 & 49 & 400 & 4.9 & Yes \\
\hline Nigeria & 124.009 & 0.28 & 45 & 46 & 390 & 4.7 & Yes \\
\hline \multirow{2}{*}{\multicolumn{8}{|c|}{ Asia-Pacific }} \\
\hline & & & & & & & \\
\hline Australia & 19.731 & $2.47(2001)$ & 78 & 83 & 21950 & 9.5 & Yes \\
\hline China & 1311.709 & $1.06(2001)$ & 70 & 73 & 1500 & 5.8 & Yes \\
\hline India & 1065.462 & $0.60(2005)$ & 60 & 63 & 540 & 6.1 & Yes \\
\hline Kazakhstan & 15.074 & 3.54 (2003) & 61 & 72 & 2350 & 2.6 & Yes \\
\hline Pakistan & 153.578 & $0.74(2004)$ & 62 & 62 & 520 & 3.2 & Yes \\
\hline Philippines & 79.999 & $0.58(2000)$ & 65 & 71 & 700 & 2.9 & Yes \\
\hline South Korea & 47.850 & 1.30 & 73 & 80 & 12720 & 8.4 & Yes \\
\hline Thailand & 62.833 & $0.37(2000)$ & 67 & 73 & 2540 & 4.4 & Yes \\
\hline \multicolumn{8}{|l|}{ Europe } \\
\hline Austria & 8.116 & 3.38 (2003) & 76 & 82 & 26810 & 7.7 & Yes \\
\hline Greece & 10.976 & $4.38(2001)$ & 76 & 81 & 13230 & 9.5 & Yes \\
\hline Portugal & 10.061 & $3.42(2003)$ & 74 & 81 & 12130 & 9.3 & Yes \\
\hline United & 59.251 & 2.30 (1997) & 76 & 81 & 28320 & 7.7 & Yes \\
\hline Kingdom & & & & & & & \\
\hline \multicolumn{8}{|l|}{ Ibero-America } \\
\hline Brazil & 178.470 & $1.15(2000)$ & 66 & 73 & 2720 & 7.9 & Yes \\
\hline Mexico & 103.457 & $1.98(2000)$ & 72 & 77 & 6290 & 6.1 & Yes \\
\hline \multicolumn{8}{|l|}{ Middle East } \\
\hline Israel & 6.433 & $3.82(2003)$ & 78 & 82 & 16240 & 9.1 & Yes \\
\hline Lebanon & 3.653 & 3.25 (2001) & 68 & 72 & 4040 & 11.5 & Yes \\
\hline Turkey & 93.586 & 1.35 (2003) & 68 & 73 & 2790 & 6.5 & Yes \\
\hline \multicolumn{8}{|l|}{ North America } \\
\hline Canada & 31.510 & $2.14(2003)$ & 78 & 82 & 24470 & 9.6 & Yes \\
\hline $\begin{array}{l}\text { United States } \\
\text { of America }\end{array}$ & 294.043 & $2.56(2000)$ & 78 & 82 & 37870 & 14.6 & Yes \\
\hline
\end{tabular}

${ }^{a}$ The World Health Report: 2006.

eg, the United Kingdom (UK) and the Netherlands. In contrast, India and Pakistan have relatively well-organized but poorly functional primary health care systems. In Portugal, health services with primary care orientation exist but lack human resources (Biscaia et al., 2006).

Family doctors often practice solo or in small groups (Bindman and Majeed, 2003). In the United States of America (USA), the corporate delivery of medical care plays a larger role. Other specialists provide primary care in several countries including Brazil and Hong Kong (The Harvard Team, 1999; Brasil, Ministério da Saúde, 2002) with alternative medical practitioners also practising primary care in many countries including Pakistan and Hong Kong (The Harvard Team, 1999).

\section{Funding of primary care}

In the UK, $80 \%$ of the revenue for the National Health Service (which includes funds for primary care) is raised from taxation. In the USA funding is $55 \%$ through private sources, mostly insurance. Government-supported insurance coverage is offered in Thailand (Towse et al., 2004). In Nigeria, voluntary organizations play a large role since public funding is insufficient. An increasing out-ofpocket expenditure for health care is seen in Israel. The establishment of a general health insurance in Turkey will unify all official insurances. Lavish funding does not guarantee results. In the USA, which has the highest per-capita expenditures in the world (US\$5711 in 2003), the life expectancy at birth is 77.3 years, which ranks it $23 \mathrm{rd}$ in the world (World Health Organization, 2006). 


\section{Problems in primary care}

\section{Quality is a problem}

Evidence-based practice is poorly implemented even in developed counties (Ebell and Frame, 2001). Nearly $45 \%$ of Americans do not receive care meeting established standards (McGlynn et al., 2003). Quality assurance in primary care is in its infancy (Lionis et al., 2004) but there is more emphasis on quality outcomes (Abyad et al., 2007). The practice of evidence-based medicine is the norm in several countries including the USA, while Kazakhstan and Turkey are moving towards it (Nugmanova, 2003; Tani ve Tedavi Rehberi, 2003).

\section{Policy and support}

Policy changes relative to health care systems are made with little input from family doctors (Cohen et al., 2001). Primary care is a priority in the national health policy of many countries, but often only on paper (Thomas et al., 2005). For example, it was reported that the Federal Mental Health Authority in Pakistan implements health policies, but does not have representation from family doctors, who provide care to most patients with psychiatric disorders (Mental Health Ordinance for Pakistan, 2001).

In Turkey, the health system is based on a centralised national policy and structure but decentralization is anticipated. Family physicians impact policy and planning of primary care services through the General Directory of Basic Health Services. In Kazakhstan, the government mandates referral to specialists for many problems (National Program of Health Sector Reform and Development in the Republic of Kazakhstan for 2005-2010, 2004). In Brazil, multiple uncoordinated gates exist for the patient to enter the health care delivery system (Stein et al., 1999).

Governments often spend funds on hospital services at the expense of primary care, making it easier for people to seek treatment from hospitals (Branco and Ramos, 2001). Reimbursement for primary care is often less than that for other specialized medical care (Woolf, 2007). However, in some countries a reversal in this trend has been seen as in Thailand (Towse et al., 2004).

\section{Education and workforce development}

Family doctors lack education and continuous professional development (CPD) opportunities in several countries (Yaman, 2002a; 2002b). In the USA, too few medical graduates select family medicine despite the country having good graduate programmes (Mackean and Gutkin, 2003). Family doctors are poorly distributed, most of them working in more affluent urban areas (Ransome et al., 1988), while in the Philippines they are retraining as nurses to secure jobs in developed countries (Choo, 2003). The involvement of family doctors in administrative tasks takes them away from clinical services exacerbating problems. The high number of patient visits and aging patients with multiple problems results in a heavy burden on the health care system (Iversen et al., 2002). In some countries the family doctor shortage is leading to overworked physicians, difficult access to care and longer waiting times (College of Family Physicians of Canada, 2004). In other countries HIV infection poses a serious challenge to health systems and hence sustainable development (Federal Ministry of Health, 2003).

\section{Research in primary care}

There is limited support for primary care research. The need for research in primary care is crucial, and developing the ability of family doctors to conduct it requires support (Beasley et al., 2007).

\section{Question 2. The role of family doctors in primary care and integration with other health care providers (alternative practitioners, traditional healers, sub-specialists)}

The role of family doctors and the degree of coordination and integration with other health care providers is quite variable across different countries.

In most countries, family doctors provide only outpatient care but in, for example, the USA and Canada, they often provide inpatient care, intensive care, maternity care and emergency care services. The provision of palliative care including homebased care is a function of family doctors in several countries including Australia and the UK (Grande et al., 2004; Hiramanek and McAvoy, 2005).

In the UK, family doctors are first-contact physicians for individuals and families. Their role 
includes prevention, clinical diagnosis, treatment and the coordination of care with medical and social services. They act as a gateway for hospital care, with some exceptions such as direct access to accident and emergency, genitourinary medicine and family planning services. In general, family doctors are skilled community-based clinicians serving as a resource to a defined practice population with strong emphasis on doctor-patient relationships. They work closely with the community nurses, nurse practitioners and social workers.

The coordination of patient care between family doctors and other specialists needs improvement in many countries. A low referral rate may reflect either the effectiveness of the family doctors or reluctance to refer for fear of losing patients (Munro et al., 1991). In those countries where family doctors work closely with other specialists, the relationship is generally positive and constructive as in the USA (Berenson, 2005). In Pakistan, the Philippines and Hong Kong, respondents commented that family doctors lack working relationships with other specialists and patients are usually referred with reluctance.

The integration of alternative medical practitioners with family doctors is uncommon despite the frequent use of their services by patients (Ness et al., 2005). Delay in seeking modern medical care has been attributed to alternative medical practitioners, resulting in adverse outcomes (Malik and Gopalan, 2003). In the Philippines it was reported that patients seek treatment from alternative medical practitioners when modern medical care fails to offer cure. Some of the alternative therapies are considered dangerous and constitute modern day quackery (Magee, 2002) but access to safe complimentary medical therapies is increasingly taking place through family doctors (Thomas et al., 2001).

Traditional birth attendants carry out the majority of deliveries in rural areas of Pakistan, but they are not integrated with other health care professionals (Safdar et al., 2002). Some steps are being taken to improve this situation (Fatmi et al., 2005). In rural Thailand, the shortage of family doctors has been partly compensated by provision of services by trained village health volunteers, midwives, sanitarians and nurse practitioners.

\section{Question 3. Anticipated changes in the health care systems and population needs in the next decade}

The conclusion from the respondents was that if no major initiatives are undertaken, the status of family doctors is unlikely to improve and government support for hospital care at the expense of primary care is likely to continue. New initiatives could contribute to increasing the recognition of the value of primary care for the health of populations.

Shortages of family doctors are likely to become worse, particularly in rural areas. Younger graduates (who include a higher proportion of women) are working fewer hours and providing a narrower range of services than their older colleagues (National Physician Survey, Canada, 2004). The growing population will put more pressure on health services, and the increase in the elderly population will pose special problems because of the number of co-morbidities and the complexity of problems (Anderson and Chu, 2007). The availability of diverse medical treatments is likely to increase the complexity of treating patient problems. Family doctors already manage multiple problems at each visit (Beasley et al., 2004) and the pressure for this is likely to increase worldwide.

Lifestyle changes will increase the prevalence of obesity and its consequent morbidities. The increasing cost of medical interventions may require rationing (Organization for Economic Cooperation and Development, 2001). The shift of hospital care to ambulatory settings will require a greater partnership with patients and their families and community resources. The appointment of specialist general practitioners in the UK to provide specialized community clinics for a cluster of practices is a debatable development. The advancement of information technology (eg, the Internet) will enable patients to participate more in their own care but may also raise patient expectations.

Increasing affluence in many areas will enable patients to visit other specialists for primary care problems, while increasing poverty in others will make the provision of even essential services a challenging task (Karkee et al., 2005).

The recognition of the need for, and the establishment of, formal training programmes for family doctors are likely to continue. The 
enforcement of certification/re-certification, CPD and quality improvement strategies will favourably impact on the prestige of family doctors.

The view was expressed that the financial support for primary care is unlikely to increase. The linking of payments to quality in relation to disease management in the USA and the UK is likely to spread to other countries. Non-governmental funding is likely to play a larger role in future in many countries, including developed western countries.

\section{Questions 4, 5 and 6. Anticipated challenges and proposed actions for family doctors and organized family medicine}

\section{A. Service provision: address quality and related issues}

\section{Ensure audit and quality assurance}

The principles and practice of continuous quality improvement should be fully enforced in primary care settings. Such activities should be transparent to enhance credibility.

\section{Promote group practices}

A move towards group practice will increase efficiency and improve patient care through collaboration and mutual learning, providing more time for CPD activities, teaching and research and reduce burnout among family doctors. Group practices involving other specialists will promote effective working relationships.

\section{Promote multidisciplinary teams}

Multidisciplinary teams that include nurses and pharmacists can provide a range of improved services while reducing family doctors' workloads and should be promoted.

\section{Incorporate information technology into practice}

Information technology is becoming easier to use, powerful, less expensive and more readily available. Patient-physician email, remote monitoring and telemedicine consultation are opportunities available to family doctors (Heinzelmann et al., 2005). Information and communication technology (ICT) can serve as a tool to improve the delivery of primary health care, through
'e-Health'. ICT includes patient and clinician communication, medical records, decision support and knowledge-based management (Ebell and Frame, 2001). There are concerns about time, cost, patient privacy, lack of reimbursement, liability, technology interoperability and disruption of the patient-physician relationship, reliability of online information and a lack of evidence for benefit (Bodenheimer and Grumbach, 2003).

Ensure appropriate coordination of patient care

Other specialists need to recognize their role in supporting, not supplanting, primary care and developing a well-functioning referral system must be a priority for family doctors (Qidwai and Maqbool, 2005). The family doctor should be the focal point for health care in the community (Souliotis and Lionis, 2004).

\section{Ensure an ethical relationship with industry}

Industry is a powerful stakeholder in health care and family doctors should develop a fruitful and ethical relationship. Conflicts of interest must be minimized and made transparent. Family doctors should participate in research and development activities with the industry.

\section{B. Education: improve education and continuing professional development}

\section{Expand and improve academic education for family doctors}

Future family doctors must address both the preventive and the curative needs of patients (Buchan and Dal Poz, 2002). The training of family doctors should be by academic family physicians and conducted in both academic and community settings. A critical mass of academic family doctors is required. National and international collaboration in education and research should be promoted.

\section{Promote CPD}

Family doctors will have to keep up to date through CPD programmes (Yaman, 2002b). Electronic means of dissemination may be useful as exemplified by the World Organization of Family Doctors (Wonca) Website (Global family doctor, 2006). 


\section{Develop support for primary care in academic institutions}

Academic institutions support the training and research of hospital specialists at the expense of primary care education and research. The ratio of academic to service practitioners in academic departments of family medicine should be increased and interaction with and support for family doctors in the community should be developed.

\section{Research: develop a robust research enterprise among family doctors}

\section{Promote primary care research}

Resources are needed to evaluate health services and health care outcomes to provide the most beneficial and cost-effective treatments. These projects can be facilitated in part by primary care research networks. A need exists in family medicine for more emphasis on research, and funding for research and journals for research publication, including a need to change the research culture (Weel and Rosser, 2004; Beasley et al., 2007). Evidence-based practice guidelines should be based on research conducted in primary care settings.

\section{Improve support for family doctors}

\section{Promote adaptability and flexibility among family doctors}

Family doctors will be required to adjust to the organizational changes and demographic shifts (Martin et al., 2004). They should adopt funding models that promote cost-effective management of chronic conditions, focus on the care needed by communities and avoid practices that primarily generate income.

\section{Improve the status of family doctors}

Vocational training in family practice, certification, CPD and re-certification will help improve the status of family doctors. Enhanced respect for family medicine will increase medical student interest in the specialty (Yaris and Dikici, 2004). Recognition should be sought for family doctors as the critical component of primary health care (College of Family Physicians of Canada, 2004). We need to study how stakeholders perceive family doctors and implement strategies to improve a family doctor's status (Abyad, 1996).
Gain support of policy makers for primary care

Family doctors and their organizations should seek policy makers' support for primary care by demonstrating the value of their services in health care delivery. The remuneration for family doctors must be similar to that of other specialists.

\section{Promote public education}

Family medicine is a new specialty in several countries (Nugmanova, 2002). The public needs to be educated about the role of family doctors and how to utilize their services.

\section{Help prevent burnout}

Organized family medicine should find ways to improve family doctors' well-being and to prevent burnout (Yaman and Ungan, 2002).

Table 2 lists the anticipated challenges, actions required and expected outcomes for future family doctors.

\section{Discussion and conclusions}

This collaborative enquiry drew on the knowledge and experiences of the members of the IFPCRN. It is therefore limited by its use of a convenience sample, based largely on the opinions of contributors, limiting any claim to generalize the findings and recommendations. This exploration has highlighted, through responses to six key questions, several issues and potential solutions that appear to be relatively consistent across the responding countries and regions, although the specifics in terms of health care systems and role of family doctors vary widely.

Common problems relating to delivery systems, funding and policy, lack of evidence-based medical practice, education and research have been identified. There is a wide variability in the role of family doctors across countries and regions, often with poor interaction with other caregivers. Despite an anticipated expansion of the family doctor model, shortages of family doctors are expected, despite an increase in the health care needs of populations.

The foremost anticipated challenge includes addressing quality issues. This requires regular audit and quality assurance initiatives, promoting adaptability, group practices and teamwork, coordinating care, incorporating information 
Table 2 Anticipated Challenges, Required Actions and Expected Outcomes for future family doctors

$\begin{array}{lll}\text { Challenge } & \text { Required action } & \text { Expected outcome }\end{array}$

A. Service provision

1. Ensure delivery of high quality clinical patient care

2. Promote group practices

3. Promote multi-disciplinary teams of family doctors, nurses, pharmacists, etc.

4. Ensure appropriate coordination of patient care

5. Incorporate information technology into practice

6. Develop more effective consultative and referral mechanisms

7. Promote ethical relationship with Industry

\section{B. Education}

1. Undergraduate teaching

\section{Postgraduate teaching}

3. Certification, continuing professional development and re-certification

4. Develop support for primary care in academic institutions

\section{Research}

1. Promote primary care research

2. Improve the knowledge base for primary care through primary care research

3. Promote evidence-based practice

D. Improve support for family doctors

1. Promote adaptability and flexibility among family doctors

2. Improved status of family doctors
Have continuous quality assurance processes in place

Support and encourage development of group practices

Support and encourage development of such teams

Steps to be taken to make family doctor the focal point for health care in the community

Take practical steps to ensure information technology is exploited to full extent in primary care

Ensure cordial relationship with other specialists

Demonstrating value of family doctors in health care delivery

Ensure adequate share in curriculum and faculty to teach. Community based teaching

Ensure availability of good quality residency training programmes.

Training by academic family doctors in hospital and community settings Ensure learning/certification cycle is in place

Ratio of academic primary care physicians should be increased

Capacity building in research among family doctors

Development of Leadership for Research (Brisbane Initiative) development of PCRNs, education about primary care research in CPE activities, development of funding base Develop EBM resources appropriate to local needs; develop graduate and CPD programmes supporting EB practice
Improved patient care, enhanced respect with public and academics Enhanced physician and patient satisfaction with more time for professional development for Physicians

Provision of better and coordinated patient services and development of cordial relations between health care providers

Better patient care and both physicians and patient satisfaction

Better provision of primary care services to the community

Better integration of family doctors with other specialists

More respect where industry is restrained from undue influence

Medical graduate with exposure to family medicine

Well trained workforce

Knowledgeable, skilled and up-to-date workforce in place

Attainment of balance for support between primary, secondary and tertiary care

Better health care for the community. Better image of family doctors among colleagues Improved knowledge base for practice and policy

Improved care, more respect with public and academics

Better, more efficient practice arrangements and enhanced patient satisfaction

Better physicians and patient satisfaction. More recruitment of medical graduates into primary care 
Table 2. Continued

\begin{tabular}{|c|c|c|}
\hline Challenge & Required action & Expected outcome \\
\hline 3. Gain policy maker's support & $\begin{array}{l}\text { Provision of excellent patient care } \\
\text { across the board }\end{array}$ & $\begin{array}{l}\text { Primary care to get its due place in health } \\
\text { care }\end{array}$ \\
\hline $\begin{array}{l}\text { 4. Promote public education } \\
\text { about family doctors }\end{array}$ & $\begin{array}{l}\text { Public education through media about } \\
\text { the role of family doctors }\end{array}$ & $\begin{array}{l}\text { Improved image and utilization of family } \\
\text { doctors }\end{array}$ \\
\hline $\begin{array}{l}\text { 5. Prevent family doctor's } \\
\text { burn out }\end{array}$ & $\begin{array}{l}\text { Find ways to promote physician well } \\
\text { being }\end{array}$ & $\begin{array}{l}\text { Improved care, more recruitment to } \\
\text { specialty }\end{array}$ \\
\hline $\begin{array}{l}\text { 6. Need to secure human and } \\
\text { material resources for an } \\
\text { effective workforce }\end{array}$ & Ensure human and material resources & $\begin{array}{l}\text { Better access to improved family } \\
\text { medicine services }\end{array}$ \\
\hline $\begin{array}{l}\text { 7. Ensure remuneration for } \\
\text { family doctors is similar to } \\
\text { other specialists }\end{array}$ & $\begin{array}{l}\text { Prove value of family doctors equal to } \\
\text { other specialists }\end{array}$ & $\begin{array}{l}\text { Better success at meeting workforce } \\
\text { needs }\end{array}$ \\
\hline
\end{tabular}

PCRN: Primary Care Research Network; CPD: continuous professional development; EBM: evidence-based medicine; EB: evidence-based.

technology into practice and ensuring ethical relationships with the industry. These measures can promote the delivery of high-quality services to the community.

Providing excellent patient care is essential for improving the status and support for family doctors. Achieving this requires continuing engagement with policy makers, academic institutions and the public. Improved education and continuing professional development opportunities are required as are measures to prevent burnout and retain the workforce. Research in primary care is fundamental to the development of relevant guidelines and to promote evidence-based medical practice.

In conclusion, it is the provision of high-quality competitive services that will ensure proper realization and utilization of the potential of family medicine to resolve common health problems at the community level. The recommended actions summarize the steps that are necessary to move the specialty forward in the coming decade.

\section{List of contributors}

A. Abyad, General authority for health services for the Emirate of Abu Dhabi, United Arab Emirates; Tariq Aziz, Pakistan Society of Family Physicians, Pakistan; Isabela Benseñor, University of São Paulo, Brazil; Aya Biderman, Ben Gurion University, Beer Sheva, Israel; André Biscaia, Board of AGO, Portugal; Manzoor A. Butt, Family Physician, Rawalpindi, Pakistan; James A. Dickinson, University of Calgary, Canada; Mustafa Fevzi Dikici, Ondokuz Mayis University School of Medicine, Department of Family Medicine, Samsun, Turkey; Tamer Edirne, Family Physician, Turkey; Paulo Ferrinho, Instituto de Higiene e Medicina Tropical, Portugal; Susan T. Go, Family Physician, Philippines; Gustavo Gusso, University of São Paulo, Brazil; Paul Heinzelmann, Harvard Medical School, USA; Chris Hogan, Victorian Faculty, Royal Australian College of General Practitioners, Australia; Victor Inem, Lagos University Hospital and the Institute of Child Health and Primary Care College of Medicine, University of Lagos, Nigeria; Cindy L. K. Lam, University of Hong Kong, Hong Kong; Christos Lionis, School of Medicine University of Crete, Greece; Manfred Maier, Medical University of Vienna, Austria; Donna P. Manca, University of Alberta, Canada; Priyesh R. Modi, Family Physician, Bharuch, Gujarat, India; Mohamed Farouk Allam, Ain Shams University Cairo, Egypt; Mabel N. Nangami, School of Public Health, Moi University, Kenya; Azhar E. Nugmanova, Almaty Postgraduate Institute for Physicians, Kazakhstan; Maeve O'Beirne, University of Calgary, Canada; Peter Nyarang'o Orotta, School of Medicine, Asmara, Eritrea; Riaz Qureshi, Aga Khan University, Pakistan; Shvartzman Pessach, Ben Gurion University, Beer Sheva, Israel, Paula Silva Family Doctor, Portugal; Helen Smith, University of Brighton, Brighton, United Kingdom; Sung Sunwoo, University of Ulsan College of Medicine, Songpa-gu, Seoul, Korea; Mehmet Ungan, Middle East Technical University, Ankara, Turkey; William Cayley, Faculty Community-based Family Medicine Residency, Rural Wisconsin, USA; Hakan Yaman, 
University of Akdeniz, Turkey; Fusun Yaris, Ondokuz Mayis University School of Medicine, Department of Family Medicine, Samsun, Turkey.

Note: In this paper the term family doctor is used as an inclusive term to include general practitioners and family physicians.

A summary of the paper was presented at the First Annual International Primary Health Care Conference, Emirate of Abu Dhabi, held in January 2006 at Abu Dhabi.

\section{References}

Abyad, A. 1996: Family medicine in the Middle East: reflections on the experiences of several countries. Journal of the American Board of Family Practice 9, 289-97.

Abyad, A., Al-Baho, A.K., Unluoglu, I., Tarawneh, M. and Al Hilfy, T.K. 2007: Development of family medicine in the Middle East. Family Medicine 39, 734-41.

Anderson, G.F. and Chu, E. 2007: Expanding priorities confronting chronic disease in countries with low income. New England Journal of Medicine 356, 209-15.

Beasley, J.W., Hankey, T.H., Erickson, R., Stange, K.C., Mundt, M., Elliott, M. et al. 2004: How many problems do family physicians manage at each encounter? AWReN study. Annals of Family Medicine 2, 405-10.

Beasley, J.W., Starfield, B., van Weel, C., Rosser, W. and Haq, C.L. 2007: Global health and primary care research. Journal of the American Board of Family Medicine 20, 518-26.

Berenson, R.A. 2005: Which way for competition? None of the above. Health Affairs 24, 1536-542.

Bindman, A.B. and Majeed, A. 2003: Organization of primary care in the United States. British Medical Journal 326, 631.

Biscaia, A., Martins, J., Carreira, M., Fronteira, I., Antunes, A. and Ferrinho, P. 2006: Cuidados de Saúde Primários em Portugal - Reformar para Novos Sucessos (Grande Prémio Fundação AstraZeneca 2005). Lisboa: Padrões Culturais Editora.

Bodenheimer, T. and Grumbach, K. 2003: Electronic technology. A spark to revitalize primary care? Journal of the American Medical Association 290, 259-64.

Branco, A. and Ramos, V. 2001: Cuidados de saúde primários em Portugal. Revista Portuguesa S Pública 5-12.

Ministério da Saúde, Brasil. 2002: O Programa Saúde da Família e a Atenção Básica no Brasil. Brasília: Ministério da Saúde. [Online] Retrieved 7 May 2008 from http:// dtr2001.saude.gov.br/bvs/publicacoes/psf_atencaobasica.pdf

Bray, J., Lee, J.A., Smith, L. and Lyle, Y. 2000: Collaborative inquiry in practice. Action, reflection and making meaning. New York: Sage Publications.
Buchan, J. and Dal Poz, M. 2002: Skill mix in the health care workforce: reviewing the evidence. Bulletin of the World Health Organization 80, 575-80.

Choo, V. 2003: Philippines losing its nurses, and now maybe its doctors. Lancet 361, 1356.

Cohen, M., Ferrier, B., Woodward, C.A. and Brown, J. 2001: Health care system reform. Ontario family physician's reactions. Canadian Family Physician 47, 1777-784.

College of Family Physicians of Canada. 2004: Family Medicine in Canada: vision for the future. [Online] Retrieved 7 May 2008 from http://www.cfpc.ca/English/ cfpc/communications/health\%20policy/Published\%20Reports/ default.asp?s $=1$

Donaldson, M., Yordy, K. and Lohr, K. 1996: Primary Care America's Health in a New Era. Washington, DC: National Academy Press.

Ebell, M.H. and Frame, P. 2001: What can technology do to, and for, family medicine? Family Medicine 33, 311-19.

Fatmi, Z., Gulzar, A.Z. and Kazi, A. 2005: Maternal and newborn care: practices and beliefs of traditional birth attendants in Sindh, Pakistan. East Mediterranean Health Journal 11, 225-34.

Federal Ministry of Health, Abuja. 2003: Technical report 2003, National HIV Sero-prevalence Sentinel Survey. Abuja: Federal Ministry of Health.

Global Family Doctor. 2006: Website for world family doctors. [Online] Retrieved 7 May 2008 from www.globalfamily doctor.com

Grande, G.E., Farquhar, M.C., Barclay, S.I. and Todd, C.J. 2004: Valued aspects of primary palliative care: content analysis of bereaved carers' descriptions. British Journal of General Practice 54, 772-78.

Heinzelmann, P.J., Lugn, N.E. and Kvedar, J.C. 2005: Telemedicine in the future. Journal of Telemedicine and Telecare 11, 384-90.

Hiramanek, N. and McAvoy, B.R. 2005: Meeting the needs of patients with cancer - a GP guide to support services. Australian Family Physician 34, 365-67.

Iversen, L., Farmer, J.C. and Hannaford, P.C. 2002: Workload pressures in rural general practice: a qualitative investigation. Scandinavian Journal of Primary Health Care 20, 139-44.

Karkee, S.B., Tamang, A.L., Gurung, Y.B., Mishra, G., BanezOckelford, J., Saunders, P. et al. 2005: Improving access to drugs by poor households through a cost sharing drug scheme: a wealth ranking approach. Nepal Medical College Journal 7, 26-31.

Lionis, C., Tsiraki, M., Bardis, B. and Philalithis, A. 2004: Seeking quality improvement in primary care in Crete, Greece: the first actions. Croatian Medical Journal 45, 599-603.

Mackean, P. and Gutkin, C. 2003: Fewer medial students selecting family medicine. Can family practice survive? Canadian Family Physician 49, 408-09.

Magee, R. 2002: Quacks: fakers and charlatans in medicine. Pharmacy History Australia 3, 9-11. 
Malik, I.A. and Gopalan, S. 2003: Use of CAM results in delay in seeking medical advice for breast cancer. European Journal of Epidemiology 18, 817-23.

Martin, J.C., Avant, R.F., Bowman, M.A., Bucholtz, J.R., Dickinson, J.R., Evans, K.L. et al. 2004: The future of family medicine: a collaborative project of the family medicine community. Annals of Family Medicine 2, (Suppl), S3-32.

McGlynn, E.A., Asch, S.M., Adams, J., Keesey, J., Hicks, J., DeCristofaro, A. et al. 2003: The quality of health care delivered to adults in the United States. New England Journal of Medicine 348, 2635-645.

Mental Health Ordinance for Pakistan. 2001: [Online] Retrieved 7 May 2008 from http://www.emro.who.int/ MNH/WHD/Pakistan-Ordinance.pdf

Munro, J.C., Lewis, J. and Lam, C.L.K. 1991: A survey of the referral patterns in Hong Kong. Hong Kong Practitioner 13, 1609-620.

National Physician Survey. 2004: Initial data release of the 2004 National Physician Survey. A collaborative project of The College of Family Physicians of Canada, The Canadian Medical Association, and The Royal College of Physicians and Surgeons of Canada. [Online] Retrieved 7 May 2008 from URL:http://www.cfpc.ca/nps/English/pdf/Research_ \&_Reports/Archived/Initial_Data_Release_2004_NPS_Oct04_ Updated_Nov.pdf

National Program of Health Sector Reform and Development in the Republic of Kazakhstan for 2005-2010. 2004: Approved by Edict of President of the Republic of Kazakhstan. No. 1438.

Ness, J., Cirillo, D.J., Weir, D.R., Nisly, N.L. and Wallace, R.B. 2005: Use of complementary medicine in older Americans: results from the Health and Retirement Study. Gerontologist 45, 516-24.

Nugmanova, D.S. 2002: PHC development. Health reforms lessons learned. Primary Health Care Conference, Karaganda, Kazakhstan, January 30-31.

Nugmanova, D.S. 2003: Clinical practice guidelines in Kazakhstan: first steps towards development and implementation. Information Bulletin for Health Professionals in Central Asia, ZdravPlus/USAID newsletter "Time to Be Healthy". [Online] Retrieved 7 May 2008 from http://www.zplus.kz/

Organization for Economic Co-operation and Development (OECD). 2001: Policy brief. OECD health at a glance how Canada compares. OECD Observer. [Online] Retrieved 7 May 2008 from http://www.oecd.org/ dataoecd/5/25/2465559.pdf

Qidwai, W. and Maqbool, M. 2005: Patient referral patterns at a family practice centre in Karachi. Medicine Today 3, 34-37.

Ransome Kuti, O., Sorungbe, A.O.O., Oyegbite, K.S. and Bamisaiye, A. 1988: Strengthening primary health care at local government level. The Nigerian experience. Lagos, Nigeria: Academy Press, Ltd.

Primary Health Care Research \& Development 2008; 9: 172-182
Safdar, S., Inam, S.N., Omair, A. and Ahmed, S.T. 2002: Maternal health care in a rural area of Pakistan. Journal of the Pakistan Medical Association 52, 308-11.

Souliotis, K. and Lionis, C. 2004: Creating an integrated health care system in Greece: a primary care perspective. Journal of Medical System 28, 643-52.

Sox, H.C. 2003: The future of primary care. Annals of Internal Medicine 4, 230-32.

Starfield, B. 1991: Primary care and health: a cross-national comparison. Journal of the American Medical Association 266, 2368-371.

Stein, A.T., Costa, M., Busnello, E.D. and Rodrigues, L.C. 1999: Who in Brazil has a personal doctor? Family Practice 16, 596-99.

Tanı ve Tedavi Rehberi. 2003: Guideline of diagnosis and treatment. Ankara: Ministry of Health.

The Harvard Team. 1999: Improving Hong Kong's Health Care System: Why and for Whom? Hong Kong SAR: Government Printing Department. The Harvard Team.

Thomas, K.J., Nicholl, J.P. and Fall, M. 2001: Access to complementary medicine via general practice. British Journal of General Practice 51, 25-30.

Thomas, S., Okorafor, O.A. and Mbatsha, S. 2005: Barriers to the equitable funding of primary healthcare in South Africa. Applied Health Economics and Health Policy 4, 183-90.

Towse, A., Mills, A. and Tangcharoensathien, V. 2004: Learning from Thailand's health reforms. British Medical Journal 328, 103-05.

Weel, C.V. and Rosser, W.W. 2004: Improving health care globally: a critical review of the necessity of family medicine research and recommendations to build research capacity. Annals of Family Medicine (Suppl 2), S5-16.

World Bank. 1993: World development report. Investing in health. Washington, DC: World Bank.

World Health Organization. 2006: World health report 2006. [Online] Retrieved 7 May 2008 from http://www.who.int/ whr/2006/annex/06_annex1_en.pdf

Woolf, S.H. 2007: Potential health and economic consequences of misplaced priorities. Journal of the American Medical Association 297, 523-26.

Yaman, H. 2002a: Training in family medicine: need for changes? [Letter]. European Journal of General Practice 8, $120-21$.

Yaman, H. 2002b: Continuing medical education in Turkey: efforts of the Turkish Medical Association. BMC Medical Education 2, 6.

Yaman, H. and Ungan, M. 2002: Burnout in young doctors [in Turkish]. Türk Psikoloji Dergisi 17, 37-44.

Yaris, F. and Dikici, M.F. 2004: Why medical students prefer other specialties rather than family medicine? Poster presented at the 17th WONCA World Conference of Family Doctors, Orlando, Florida, USA, October 13-17. 